\title{
Negative association of acetate with visceral adipose tissue and insulin levels
}

This article was published in the following Dove Press journal:

Diabetes, Metabolic Syndrome and Obesity:Targets and Therapy 29 February 2012

Number of times this article has been viewed

\author{
Brian T Layden' \\ Sudha K Yalamanchi' \\ Thomas MS Wolever ${ }^{2}$ \\ Andrea Dunaif' \\ William L Lowe Jr' \\ 'Division of Endocrinology, \\ Metabolism and Molecular Medicine \\ (BTL, SKY, AD, WLL), Northwestern \\ University Feinberg School of \\ Medicine, Chicago, Illinois, USA; \\ ${ }^{2}$ Department of Nutritional Sciences \\ (TMSW), University of Toronto, \\ Toronto, Canada
}

Background: The composition of gut flora has been proposed as a cause of obesity, a major risk factor for type 2 diabetes. The objective of this study was to assess whether serum short chain fatty acids, a major by-product of fermentation in gut flora, are associated with obesity and/or diabetes-related traits (insulin sensitivity and secretion).

Methods: The association of serum short chain fatty acids levels with measures of obesity was assessed using body mass index, computerized tomography scan, and dual photon X-ray absorptiometry scan. Insulin sensitivity and insulin secretion were both determined from an oral glucose tolerance test and insulin sensitivity was also determined from a hyperinsulinemic euglycemic clamp.

Results: In this population of young, obese women, acetate was negatively associated with visceral adipose tissue determined by computerized tomography scan and dual photon X-ray absorptiometry scan, but not body mass index. The level of the short chain fatty acids acetate, but not propionate or butyrate, was also negatively associated with fasting serum insulin and 2 hour insulin levels in the oral glucose tolerance test.

Conclusions: In this population, serum acetate was negatively associated with visceral adipose tissue and insulin levels. Future studies need to verify these findings and expand on these observations in larger cohorts of subjects.

Keywords: obesity, insulin, gut flora, short chain fatty acids

\section{Introduction}

Recently, a possible association between the composition of the gut flora and obesity has been proposed. ${ }^{1-3}$ Of importance, it is well described that, in the gut, these bacteria engage in fermentation of certain foods. ${ }^{4}$ One by-product of fermentation is short chain fatty acids (SCFAs). Because SCFAs are predominantly made in the gut, much of the research on the action of SCFAs has focused on their role in gastrointestinal disease. ${ }^{5}$ However, SCFAs derived from fermentation are also present in the systemic circulation. ${ }^{6}$ The major SCFA in systemic circulation is acetate $(\mathrm{C} 2)$, with lower concentrations of propionate (C3), and butyrate (C4). ${ }^{6}$ As SCFAs may be involved in the association of gut flora with the development of obesity, we examined the association of serum SCFA levels with measures of obesity. ${ }^{7}$

Obesity is a major risk factor for developing insulin resistance. This insulin resistance leads pancreatic beta cells to secrete more insulin, and if the beta cells cannot maintain this higher level of insulin secretion, hyperglycemia occurs and diabetes can develop. ${ }^{8}$ Understanding how obesity leads to impaired insulin sensitivity and why pancreatic beta cells may fail to secrete sufficient insulin are important questions. 
Certain nutrients derived from the diet, such as amino acids and free fatty acids, ${ }^{9,10}$ appear to be involved in both these processes. For example, long chain fatty acids (LCFAs) have a well-defined role in both insulin secretion and sensitivity, ${ }^{11}$ and consequently, have an important role in the development of insulin resistance and diabetes. Moreover, LCFAs can be a fuel to stimulate insulin secretion, but chronic overexposure of LCFAs to beta cells leads to impairment in insulin secretion; likewise, chronic overexposure to LCFAs leads to insulin resistance. ${ }^{11}$

Importantly, LCFAs are distinct from SCFAs in several respects. At the molecular level, LCFAs are larger, more water insoluble, and contain over twelve carbons; whereas SCFAs are water soluble and contain less than five to six carbons. ${ }^{5}$ LCFAs are derived primarily from fatty foods, whereas SCFAs are derived, at least partially, from fermentation that occurs within the colon. ${ }^{5}$ To date, limited studies have examined whether SCFAs are mediators of either insulin action or secretion in humans. One study found a positive correlation between propionate and butyrate, but not acetate, with steady state plasma glucose, an indirect measure of insulin sensitivity. ${ }^{6}$ Even less is known about the role of SCFAs in insulin secretion. In vitro studies with rodent islets suggested an inhibitory effect of SCFAs on glucose-stimulated insulin secretion. ${ }^{12}$ In this study, we examined whether serum SCFA levels are associated with insulin action and/or secretion.

\section{Methods}

\section{Subjects}

The study was approved by the Institutional Review Board of Northwestern University. All subjects gave written, informed consent. In this cohort of obese (defined as body mass index [BMI] over 30$)$ subjects $(n=18)$, a total of seven obese women with polycystic ovary syndrome (PCOS) and eleven obese women without PCOS were included. All the women were otherwise in good health and not taking medications known to affect carbohydrate metabolism for at least one month prior to the study, including no antibiotics, probiotics, or prebiotics. None of the subjects had fasting glucose values diagnostic of diabetes mellitus (Supplemental Table 1), based on the American Diabetes Association criteria. ${ }^{13}$ Women without PCOS had regular menstrual cycles (every 27-35 days) and were without clinical or biochemical evidence of hyperandrogenism. Women with PCOS had irregular menstrual cycles ( $\leq 6$ menses per year) and elevated total testosterone and/or bioavailable testosterone. ${ }^{14}$ Other diagnoses were excluded in the women with PCOS as described previously. ${ }^{15}$ Height, weight, and blood pressure were obtained, and BMI was determined in all subjects. Serum acetate, propionate, and butyrate were measured in a fasting serum sample by gas chromatography as before. ${ }^{16}$ Briefly, an $800 \mu \mathrm{L}$ serum aliquot was filtered and the proteinfree filtrate was stored at $20^{\circ} \mathrm{C}$ before vacuum distillation. The distillation was performed using a $225 \mu \mathrm{L}$ protein-free sample with a $25 \mu \mathrm{L}$ internal standard solution added. ${ }^{16} \mathrm{Next}$, gas chromatography was performed ${ }^{16}$ and SCFA concentrations determined as before. ${ }^{16}$

\section{Body composition and fat distribution}

All participants who fulfilled the study entry criteria had their body composition determined by dual photon X-ray absorptiometry (DEXA) (Hologic, Bedford, MA) as described before $^{17}$ and visceral adipose tissue (VAT) determined by computerized tomography (CT) scan (Siemens, Munich, Germany), with slice analysis from the L2-3 vertebral interspace. $^{18}$

\section{Metabolic testing}

For 3 days prior to the study, all subjects were advised to consume a $300 \mathrm{~g} /$ day carbohydrate weight-maintaining diet. All subjects underwent a 75 gm oral glucose tolerance test (OGTT) in the morning after an overnight fast (10-12 hours). Glucose and insulin levels were obtained every 30 minutes for 3 hours.

Sequential three-dose hyperinsulinemic euglycemic clamps were performed as previously described. ${ }^{15}$ Briefly, a retrograde placed catheter in a hand vein heated to above $40^{\circ} \mathrm{C}$ was used for collection of arterialized blood samples. A second catheter was placed in the antecubital vein. A primed, continuous infusion of $\left[6,6^{2} \mathrm{H}\right]$-glucose (Isotec, Miamisburg, $\mathrm{OH}$ ) was infused at a dose of $0.065 \mathrm{mg} / \mathrm{min} / \mathrm{kg}$ for 3 hours before initiation of the insulin infusion. After baseline glucose and insulin levels were obtained, a primed continuous infusion of insulin was started at a dose of $10 \mathrm{mU} / \mathrm{m}^{2} / \mathrm{min}$. Somatostatin was concurrently infused at a dose of $30 \mathrm{ng} / \mathrm{kg} / \mathrm{min}$, suppressing endogenous insulin secretion so that plasma insulin levels could be matched across the study groups. After 150 minutes, the insulin infusion was increased to $20 \mathrm{mU} / \mathrm{m}^{2} / \mathrm{min}$ for 150 minutes and then increased to a dose of $400 \mathrm{mU} / \mathrm{m}^{2} / \mathrm{min}$ for 90 minutes, as this is the dose at which maximal rates of insulin-mediated glucose disposal are achieved. ${ }^{17}$ The glucose levels were clamped with a variable infusion of $20 \%$ glucose enriched to $1.6 \%$ atom percent excess with $\left[6,6^{2} \mathrm{H}\right]$-glucose. Arterialized blood samples were obtained every 5 minutes for glucose, every 15 minutes for insulin, and every 10 minutes 
at baseline and during the last 40 minutes of each insulin infusion dose for $\left[6,6^{2} \mathrm{H}\right]$-glucose. Endogenous glucose production (EGP) and insulin mediated glucose disposal (IMGD) were calculated as before, ${ }^{15}$ and the maximal IMGD was used for analyses. The disposition index was calculated as the product of the clamp insulin sensitivity (defined as glucose disposal corrected for change in plasma insulin from baseline) by insulin response during the OGTT (0-30 minute, $\Delta \mathrm{I} 30)$. Of note, disposition index values were only able to be calculated for 13 of the 18 subjects.

\section{Statistical analysis}

Values are reported as the mean $+\mathrm{SD}$ unless otherwise indicated. $P$-values were calculated by Student's $t$-test (twotailed) with a significance level at $P<0.05$ using GraphPad Prism 5 (GraphPad Software, Inc, San Diego, CA). Pearson product-moment correlation coefficients were determined with GraphPad Prism 5.

\section{Results}

\section{Population characteristics}

A group of 18 obese Caucasian women were studied. Seven of these subjects had a diagnosis of PCOS. Besides the expected differences in serum testosterone, unbound testosterone, and DHEA-S between women with and without PCOS, there were no differences in age, height, weight, BMI, waist circumference, and blood pressure (Table 1). Serum SCFA levels also did not differ between the two groups (Table 1).

Table I Descriptive characteristics and short chain fatty acid levels in a cohort of 18 obese women

\begin{tabular}{|c|c|c|c|c|}
\hline Variables & $\begin{array}{l}\text { Total } \\
(\mathrm{n}=18)\end{array}$ & $\begin{array}{l}\text { PCOS } \\
(n=7)\end{array}$ & $\begin{array}{l}\text { Non-PCOS } \\
(n=I I)\end{array}$ & $P^{a}$ \\
\hline Age (years) & $29(5)$ & $29(4)$ & $28(6)$ & 0.83 \\
\hline Height $(\mathrm{cm})$ & $162(8)$ & $160(8)$ & $163(9)$ & 0.54 \\
\hline Weight (kg) & $96(17)$ & $90(22)$ & $100(12)$ & 0.26 \\
\hline Systolic BP (mm Hg) & $115(9)$ & $113(10)$ & $116(8)$ & 0.50 \\
\hline Diastolic BP (mm Hg) & $69(7)$ & $69(8)$ & $70(6)$ & 0.89 \\
\hline BMI $\left(\mathrm{kg} / \mathrm{m}^{2}\right)$ & $37(7)$ & $35(6)$ & $38(8)$ & 0.36 \\
\hline Waist (cm) & $105(12)$ & $103(14)$ & $106(11)$ & 0.56 \\
\hline Testosterone (ng/dL) & $40(30)$ & $66(34)$ & $24(7)$ & 0.0009 \\
\hline uTestosterone (ng/dL) & $16(12)$ & $27(12)$ & $9(3)$ & 0.0002 \\
\hline DHEA-S (ng/mL) & $1715(840)$ & $2364(8 \mid 8)$ & $1303(564)$ & 0.005 \\
\hline SHBG (nmol/L) & $36(18)$ & $38(20)$ & $34(18)$ & 0.72 \\
\hline Acetate $(\mu \mathrm{M})$ & $24.8(12.1)$ & $21.1(14.9)$ & $27.2(9.9)$ & 0.31 \\
\hline Propionate $(\mu \mathrm{M})$ & I.4 (0.3) & I.3 (0.2) & I.4 (0.3) & 0.55 \\
\hline Butyrate $(\mu \mathrm{M})$ & $0.5(0.2)$ & $0.5(0.2)$ & $0.5(0.2)$ & 0.74 \\
\hline
\end{tabular}

Notes: Values are the mean and standard deviation (in parentheses). ${ }^{2}$-values are shown in this column comparing parameters between PCOS versus non-PCOS subjects.

Abbreviations: PCOS, polycystic ovary syndrome; BP, blood pressure; BMI, body mass index; uTestosterone, bioavailable testosterone; DHEA-S, dehydroepiandrosterone sulfate; SHBG, sex hormone-binding globulin.
No difference in measures of obesity was observed in this cohort based on PCOS diagnosis (Supplemental Table 1). The only differences between the PCOS and non-PCOS subjects in measures from the OGTT were the 2-hour insulin and glucose levels (Supplemental Table 1). Specifically, the 2-hour glucose and 2-hour insulin levels in the PCOS subjects were higher $(P<0.05)$ than the non-PCOS subjects, which is an expected difference (see discussion). No other difference in measures derived from the OGTT and hyperinsulinemic euglycemic clamp studies were observed in this cohort based on PCOS diagnosis (Supplemental Table 1).

\section{Association of SCFAs with obesity and insulin sensitivity/secretion}

When the participants were considered as a single cohort, BMI was not correlated with fasting serum SCFA levels (Table 2), but serum acetate was negatively correlated $(P<0.05)$ with VAT as determined by CT scan (Table 2 and Figure 1A). Propionate and butyrate were not correlated with VAT. Serum acetate levels were also negatively correlated with fasting and 2-hour insulin levels in the OGTT (Table 2 and Figure 1B). Propionate and butyrate levels were not correlated with any measures determined from the OGTT. In this population, there were no significant correlations of SCFA

Table 2 Associations between short chain fatty acids and measures of obesity and insulin action/secretion

\begin{tabular}{llll}
\hline Measures & $\begin{array}{l}\text { Acetate } \\
(\mu \mathrm{M})\end{array}$ & $\begin{array}{l}\text { Propionate } \\
(\mu \mathrm{M})\end{array}$ & $\begin{array}{l}\text { Butyrate } \\
(\mu \mathrm{M})\end{array}$ \\
\hline Obesity & & & \\
BMI $\left(\mathrm{kg} / \mathrm{m}^{2}\right)$ & -0.16 & -0.02 & 0.16 \\
VAT & $-0.52(0.03)^{\mathrm{a}}$ & 0.16 & 0.15 \\
FAT $(\mathrm{kg})$ & -0.38 & 0.31 & 0.11 \\
OGTT & & & \\
Fasting glucose $(\mathrm{mg} / \mathrm{dL})$ & -0.21 & 0.04 & 0.22 \\
2-hour glucose $(\mathrm{mg} / \mathrm{dL})$ & -0.43 & -0.08 & 0.01 \\
Fasting insulin $(\mu \mathrm{U} / \mathrm{mL})$ & $-0.56(0.02)^{\mathrm{a}}$ & 0.25 & 0.21 \\
2-hour insulin $(\mu \mathrm{U} / \mathrm{mL})$ & $-0.63(0.01)^{\mathrm{a}}$ & 0.24 & 0.32 \\
Clamp & & & \\
EGP $\left(\mathrm{mg} / \mathrm{m}^{2} / \mathrm{min}\right)$ & 0.31 & 0.43 & 0.34 \\
DI $(\mathrm{IS} \times \Delta \mathrm{I} 30)$ & -0.20 & 0.09 & -0.06 \\
MCR $(\mathrm{mL} / \mathrm{min})$ & -0.09 & 0.19 & -0.25 \\
IMGD $\left(\mathrm{mg} / \mathrm{m}^{2} / \mathrm{min}\right)$ & 0.33 & -0.13 & 0.28 \\
\hline
\end{tabular}

Notes: aP-values reaching statistical significance are indicated in the parentheses. VAT was determined by computerized tomography scan, and FAT was determined by dual photon X-ray absorptiometry scan. Values are the correlation coefficients (Pearson) between short chain fatty acids and measures of obesity and values derived from the oral glucose tolerance test and hyperinsulinemic euglycemic clamp.

Abbreviations: BMI, body mass index; VAT, visceral adipose tissue; FAT, percentage fat mass $\times$ body weight; OGTT, oral glucose tolerance test; EGP, endogenous glucose production; DI, disposition index; MCR, metabolic clearance rate of insulin; IMGD, insulin mediated glucose disposal. 


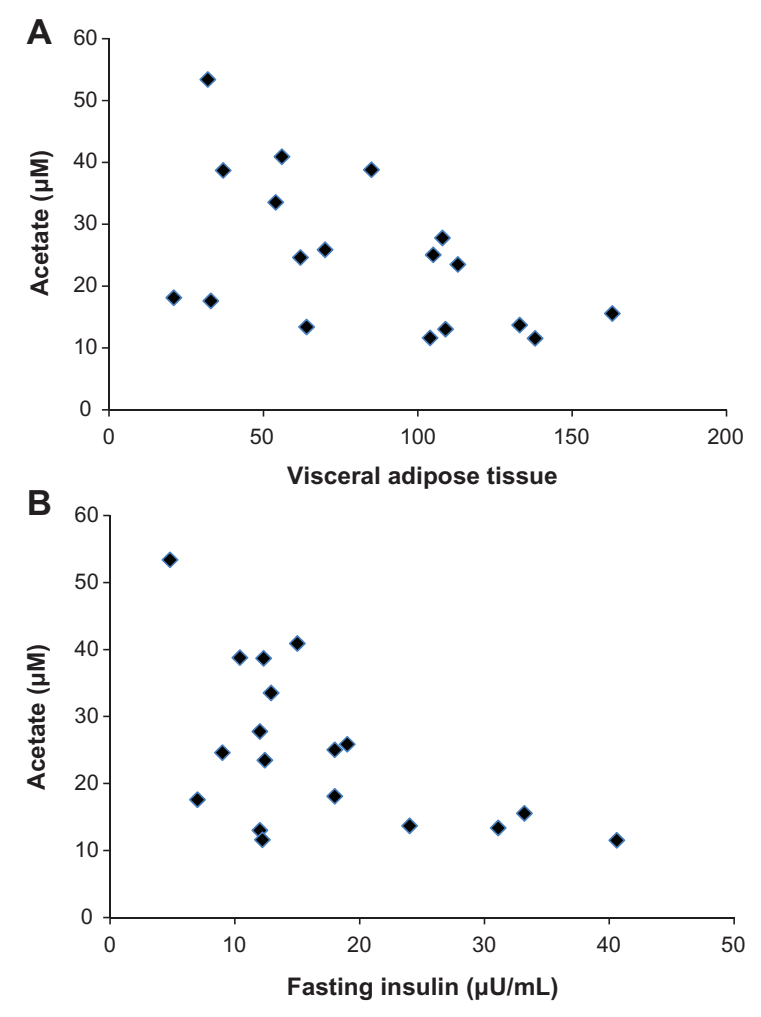

Figure I Scatter plots showing the association between acetate and visceral adipose tissue $(\mathbf{A})$ and fasting insulin (B).

levels with measures determined from the hyperinsulinemic euglycemic clamp studies (Table 2).

Next, we examined the groups separately based on PCOS diagnosis. As seen in Supplemental Table 2, similar correlations of acetate with VAT were observed for non-PCOS and PCOS subjects, compared to that observed when the groups were analyzed together (Table 2), but these correlations did not reach statistical significance (Supplemental Table 2). Likewise, when participants were stratified based on PCOS diagnosis, similar correlations between acetate with fasting and 2-hour insulin levels from the OGTT data were observed (Supplemental Table 2) to those observed considering the cohort together (Table 2). However, the association between acetate and fasting insulin was the only correlation that reached statistical significance in the non-PCOS cohort (Supplemental Table 2).

\section{Discussion}

Fatty acids have well described roles in both obesity and insulin sensitivity and secretion. ${ }^{19}$ However, most studies have focused on LCFAs containing more than twelve carbons. Little is known about the role of SCFAs (less than six carbon atoms) in these processes. Because of this, we examined the relationship between SCFAs and measures of adiposity.
Our results demonstrate the novel observation that serum acetate levels are negatively associated with VAT. Interestingly, BMI was not associated with serum acetate levels. While it is not clear why BMI, which is closely related to VAT, was not correlated with serum acetate levels, it is important to note that VAT is, in general, considered a more accurate measure of adiposity than BMI. ${ }^{20}$ Additionally, VAT is thought to be the metabolically active fat as it is strongly associated with metabolic disease. ${ }^{21}$ This likely relates, in part, to the drainage of blood from VAT into the portal system where it can affect liver nutrient metabolism; this is different than the drainage of blood from subcutaneous adipose tissue. ${ }^{22}$ Given the important role of VAT, the novel association observed here needs to be further explored.

In this study, only the level of acetate, and not levels of the other SCFAs, was correlated with VAT. Importantly, acetate is the major SCFA generated during gut fermentation and is also the only SCFA to reach high levels in the general systemic circulation. ${ }^{5}$ The other SCFAs, propionate and butyrate, are thought to be more quickly metabolized in the body upon absorption. ${ }^{5}$ However, it should be mentioned that other sources of SCFAs besides the gut exist, so it cannot be concluded that gut-derived acetate alone is associated with VAT. Furthermore, regarding acetate metabolism, other processes, including aging, ${ }^{23}$ alcohol use, ${ }^{24}$ and comorbid illnesses ${ }^{25,26}$ can lead to altered acetate levels.

While the data in the present study suggest an association of a SCFA with adiposity, an important question is the mechanism underlying this association. One potential mechanism is via binding of SCFAs to GPR41 and GPR43, the known receptors for SCFAs. These receptors have been shown to have a role in regulating leptin and glucagon-like pepetide-1 secretion, two hormones involved in regulating adiposity. ${ }^{27,28}$ Interestingly, GPR41 and GPR43 are expressed broadly including in immune cells, ${ }^{29}$ adipose tissue,${ }^{30}$ distal ileum/colon, ${ }^{31,32}$ skeletal muscle, ${ }^{33}$ and pancreatic islets. ${ }^{34}$ With this broad tissue distribution of these receptors, determining precisely how these receptors may be related to adiposity will require more extensive investigation.

We also examined the relationship between serum SCFAs and insulin action/secretion as determined from an OGTT and hyperinsulinemic euglycemic clamp. We found that serum acetate was negatively correlated with fasting insulin and 2-hour insulin in the OGTT. This relationship may be explained by the association between VAT and fasting insulin, ${ }^{35}$ as these two parameters had a strong positive association in this study (Pearson correlation coefficient $=0.66$, $P<0.003)$. Moreover, the association of VAT and fasting 
insulin with acetate levels was interdependent, as the relationship of VAT to acetate was not significant when controlling for fasting insulin (and vice versa), as determined in multiple regression analysis (data not shown).

An important limitation of this study is that this cohort included both non-PCOS and PCOS subjects. As expected, these two groups of subjects exhibited differences in androgen levels as well as measures from the OGTT. However, no differences between the groups were observed in the measures from the clamp studies, even though there is known to be other differences in matched populations of PCOS versus non-PCOS subjects, specifically IMGD. ${ }^{15} \mathrm{~A}$ difference in IMGD was not observed here, likely because the PCOS and non-PCOS cohorts were not matched and also the sample size was small. However, trends in IMGD were seen in the expected direction (Supplemental Table 1). Importantly, the major correlations between acetate with VAT and insulin levels that were observed when considering the cohort together were similar to correlations when the cohort was stratified by PCOS diagnosis, suggesting that the observed associations may be independent of the diagnosis of PCOS.

Other limitations of this study include the small sample size and a relatively homogenous population, as all the subjects were obese women. Moreover, variables that alter acetate levels such as age, alcohol intake, and other illnesses were not controlled for in this study. However, the novel findings here of an association of acetate levels with metabolically active visceral fat and insulin levels merits further study in larger and more diverse cohorts. For example, it will be important to determine if the association of serum acetate with VAT is present in non-obese and/or type 2 diabetic populations. In summary, these data provide the first evidence of an association between serum acetate levels and measures of obesity and insulin levels.

\section{Acknowledgments}

BT Layden is supported in part by Grant Number K12 HD055884 from the Eunice Kennedy Shriver National Institute of Child Health and Human Development and also by an Endocrine Fellows Foundation Grant.

\section{Disclosure}

The authors declare no conflicts of interest in this work.

\section{References}

1. Turnbaugh PJ, Backhed F, Fulton L, Gordon JI. Diet-induced obesity is linked to marked but reversible alterations in the mouse distal gut microbiome. Cell Host Microbe. 2008;3(4):213-223.

2. Turnbaugh PJ, Gordon JI. The core gut microbiome, energy balance and obesity. J Physiol. 2009;587(Pt 17):4153-4158.
3. Turnbaugh PJ, Ley RE, Mahowald MA, Magrini V, Mardis ER, Gordon JI. An obesity-associated gut microbiome with increased capacity for energy harvest. Nature. 2006;444(7122):1027-1031.

4. Samuel BS, Shaito A, Motoike T, et al. Effects of the gut microbiota on host adiposity are modulated by the short-chain fatty-acid binding G protein-coupled receptor, Gpr41. Proc Nat Acad Sci U SA. 2008;105(43):16767-16772.

5. Wong JM, de Souza R, Kendall CW, Emam A, Jenkins DJ. Colonic health: fermentation and short chain fatty acids. J Clin Gastroenterol. 2006;40(3):235-243.

6. Wolever TM, Josse RG, Leiter LA, Chiasson JL. Time of day and glucose tolerance status affect serum short-chain fatty acid concentrations in humans. Metabolism. 1997;46(7):805-811.

7. Schwiertz A, Taras D, Schafer K, et al. Microbiota and SCFA in lean and overweight healthy subjects. Obesity (Silver Spring). 2010;18(1)190-195.

8. Ferrannini E, Natali A, Bell P, Cavallo-Perin P, Lalic N, Mingrone G. Insulin resistance and hypersecretion in obesity. European Group for the Study of Insulin Resistance (EGIR). J Clin Invest. 1997;100(5):1166-1173.

9. Schenk S, Saberi M, Olefsky JM. Insulin sensitivity: modulation by nutrients and inflammation. J Clin Invest. 2008;118(9):2992-3002.

10. Sivan E, Boden G. Free fatty acids, insulin resistance, and pregnancy. Curr Diab Rep. 2003;3(4):319-322.

11. Nolan CJ, Madiraju MS, Delghingaro-Augusto V, Peyot ML, Prentki M. Fatty acid signaling in the beta-cell and insulin secretion. Diabetes. 2006;55 Suppl 2:S16-S23.

12. Ximenes HM, Hirata AE, Rocha MS, Curi R, Carpinelli AR. Propionate inhibits glucose-induced insulin secretion in isolated rat pancreatic islets. Cell Biochem Func. 2007;25(2):173-178.

13. American Diabetes Association. Standards of medical care in diabetes - 2010. Diabetes Care. 2010;33 Suppl 1:S11-S61.

14. Legro RS, Driscoll D, Strauss JF 3rd, Fox J, Dunaif A. Evidence for a genetic basis for hyperandrogenemia in polycystic ovary syndrome. Proc Nat Acad Sci U SA. 1998;95(25):14956-14960.

15. Dunaif A, Wu X, Lee A, Diamanti-Kandarakis E. Defects in insulin receptor signaling in vivo in the polycystic ovary syndrome (PCOS). Am J Physiol. 2001;281(2):E392-E399.

16. Vogt JA, Pencharz PB, Wolever TM. L-Rhamnose increases serum propionate in humans. Am J Clin Nutr. 2004;80(1):89-94.

17. Dunaif A, Segal KR, Shelley DR, Green G, Dobrjansky A, Licholai T. Evidence for distinctive and intrinsic defects in insulin action in polycystic ovary syndrome. Diabetes. 1992;41(10):1257-1266.

18. Jensen MD, Kanaley JA, Reed JE, Sheedy PF. Measurement of abdominal and visceral fat with computed tomography and dual-energy x-ray absorptiometry. Am J Clin Nutr. 1995;61(2):274-278.

19. Lopez S, Bermudez B, Abia R, Muriana FJ. The influence of major dietary fatty acids on insulin secretion and action. Curr Opin Lipidol. 2010;21(1):15-20.

20. Despres JP, Lemieux I, Prud'homme D. Treatment of obesity: need to focus on high risk abdominally obese patients. $B M J$. 2001;322(7288):716-720.

21. Demerath EW, Reed D, Rogers N, et al. Visceral adiposity and its anatomical distribution as predictors of the metabolic syndrome and cardiometabolic risk factor levels. Am J Clin Nutr. 2008;88(5): $1263-1271$.

22. Rytka JM, Wueest S, Schoenle EJ, Konrad D. The portal theory supported by venous drainage-selective fat transplantation. Diabetes. 2011;60(1):56-63.

23. Skutches CL, Holroyde CP, Myers RN, Paul P, Reichard GA. Plasma acetate turnover and oxidation. J Clin Invest. 1979;64(3):708-713.

24. Manzo-Avalos S, Saavedra-Molina A. Cellular and mitochondrial effects of alcohol consumption. Int J Environ Res Public Health. 2010;7(12):4281-4304.

25. Pouteau E, Piloquet H, Maugeais P, et al. Kinetic aspects of acetate metabolism in healthy humans using [1-13C] acetate. Am J Physiol. 1996;271(1 Pt 1):E58-E64. 
26. Tollinger CD, Vreman HJ, Weiner MW. Measurement of acetate in human blood by gas chromatography: effects of sample preparation, feeding, and various diseases. Clin Chem. 1979;25(10):1787-1790.

27. Zaibi MS, Stocker CJ, O'Dowd J, et al. Roles of GPR41 and GPR43 in leptin secretory responses of murine adipocytes to short chain fatty acids. FEBS Lett. 2010;584(11):2381-2386.

28. Tolhurst G, Heffron H, Lam YS, et al. Short-chain fatty acids stimulate glucagon-like peptide-1 secretion via the G-protein-coupled receptor FFAR2. Diabetes. 2012;61(2):364-371.

29. Brown AJ, Goldsworthy SM, Barnes AA, et al. The Orphan G proteincoupled receptors GPR41 and GPR43 are activated by propionate and other short chain carboxylic acids. J Biol Chem. 2003;278(13): 11312-11319.

30. Hong YH, Nishimura Y, Hishikawa D, et al. Acetate and propionate short chain fatty acids stimulate adipogenesis via GPCR43. Endocrinology. 2005;146(12):5092-5099.
31. Karaki S, Mitsui R, Hayashi H, et al. Short-chain fatty acid receptor, GPR43, is expressed by enteroendocrine cells and mucosal mast cells in rat intestine. Cell Tissue Res. 2006;324(3):353-360.

32. Karaki S, Tazoe H, Hayashi H, et al. Expression of the short-chain fatty acid receptor, GPR43, in the human colon. $J$ Mol Histol. 2008;39(2):135-142.

33. Nilsson NE, Kotarsky K, Owman C, Olde B. Identification of a free fatty acid receptor, FFA2R, expressed on leukocytes and activated by short-chain fatty acids. Biochem Biophys Res Commun. 2003;303(4):1047-1052.

34. Regard JB, Kataoka H, Cano DA, et al. Probing cell type-specific functions of G(i) in vivo identifies GPCR regulators of insulin secretion. J Clin Invest. 2007;117(12):4034-4043.

35. Gutin B, Johnson MH, Humphries MC, et al. Relationship of visceral adiposity to cardiovascular disease risk factors in black and white teens. Obesity (Silver Spring). 2007;15(4):1029-1035. 


\section{Supplementary tables}

Table SI Obesity, oral glucose tolerance test and hyperinsulinemic euglycemic clamp data in a cohort of 18 obese women ${ }^{\mathrm{a}}$

\begin{tabular}{|c|c|c|c|c|}
\hline Measures & Total $(n=18)$ & $\operatorname{Pcos}(n=7)$ & Non-PCOS $(n=I I)$ & $P^{b}$ \\
\hline \multicolumn{5}{|l|}{ Obesity } \\
\hline VAT & $83(10)$ & $75(16)$ & $87(13)$ & 0.54 \\
\hline FAT $(\mathrm{kg})$ & $39(3)$ & $38(6)$ & $40(3)$ & 0.69 \\
\hline \multicolumn{5}{|l|}{ OGTT } \\
\hline Fasting glucose (mg/dL) & $93.6(1.4)$ & $92.4(2.5)$ & $94.3(2.5)$ & 0.83 \\
\hline 2 hour glucose $(\mathrm{mg} / \mathrm{dL})$ & $117.9(5.8)$ & | $32.7(9.2)$ & $108.6(6.2)$ & 0.048 \\
\hline Fasting insulin $(\mu \mathrm{U} / \mathrm{mL})$ & $16.9(2.3)$ & $15.9(3.5)$ & $17.5(3.1)$ & 0.54 \\
\hline 2 hour insulin $(\mu \mathrm{U} / \mathrm{mL})$ & $83.8(12.4)$ & II $4.0(21.2)$ & $64.5(12.6)$ & 0.038 \\
\hline \multicolumn{5}{|l|}{ Clampc } \\
\hline $\operatorname{EGP}\left(\mathrm{mg} / \mathrm{m}^{2} / \mathrm{min}\right)$ & $78.9(4.5)$ & $78.3(6.1)$ & $79.3(6.5)$ & 0.92 \\
\hline $\mathrm{DI}(\mathrm{IS} \times \Delta \mathrm{I} 30)$ & $21.9(2.8)$ & $21.2(3.6)$ & $22.6(3.5)$ & 0.81 \\
\hline MCR (mL/min) & $320.3(21.8)$ & $295.8(28.6)$ & $338.6(31.4)$ & 0.35 \\
\hline IMGD (mg/m²/min) & $510.6(26.0)$ & $477.2(39.2)$ & $535.6(34.1)$ & 0.28 \\
\hline
\end{tabular}

Notes: ${ }^{a}$ Values are the mean and standard error of mean (in parentheses); ${ }^{\mathrm{P}}$-values are shown in this column comparing parameters between PCOS versus non-PCOS subjects; VAT was determined by computerized tomography scan, and FAT was determined by dual photon X-ray absorptiometry scan; cfor the hyperinsulinemic euglycemic clamp studies, the basal and steady state glucose $(\mathrm{mg} / \mathrm{dL}$ ) levels (mean $\pm \mathrm{SD}$ ) were $84.4 \pm 4.1, \mathrm{n}=18$ and $84.1 \pm 3.9, \mathrm{n}=15$ and the basal and steady state insulin $(\mu \mathrm{U} / \mathrm{mL})$ levels (mean $\pm S D, n=18$ ) were I6.I $\pm 7.1, n=18$, and I853 $\pm 258, n=15$; there were no statistical differences in these values between non-PCOS and PCOS subjects. Abbreviations: PCOS, polycystic ovary syndrome; VAT, visceral adipose tissue; FAT, percentage fat mass $\times$ body weight; OGTT, oral glucose tolerance test; EGP, endogenous glucose production; DI, disposition index; MCR, metabolic clearance rate of insulin; IMGD, insulin mediated glucose disposal.

Table S2 Associations between short chain fatty acids and measures of obesity and insulin action/secretion based on PCOS status ${ }^{\mathrm{a}}$

\begin{tabular}{|c|c|c|c|}
\hline Measures & Acetate $(\mu \mathrm{M})$ & Propionate $(\mu \mathrm{M})$ & Butyrate $(\mu \mathrm{M})$ \\
\hline \multicolumn{4}{|l|}{ Obesity } \\
\hline BMI $\left(\mathrm{kg} / \mathrm{m}^{2}\right)$ & $-0.04,-0.43$ & $-0.02,0.46$ & $-0.10,0.25$ \\
\hline VAT & $-0.60,-0.58$ & $0.11,0.21$ & $-0.04,0.52$ \\
\hline FAT (kg) & $-0.22,-0.52$ & $0.04,0.66$ & $0.16,0.08$ \\
\hline \multicolumn{4}{|l|}{ OGTT } \\
\hline Fasting glucose (mg/dL) & $-0.29,-0.25$ & $0.10,-0.16$ & $0.02,0.54$ \\
\hline 2 hour glucose (mg/dL) & $-0.5 \mathrm{I},-0.24$ & $0.10,-0.21$ & $-0.30,0.33$ \\
\hline Fasting insulin $(\mu \mathrm{U} / \mathrm{mL})$ & $-0.62(0.04),{ }^{b}-0.66$ & $0.22,0.32$ & $-0.07,0.8 \mathrm{I}(0.03)^{\mathrm{b}}$ \\
\hline 2 hour insulin $(\mu \mathrm{U} / \mathrm{mL})$ & $-0.54,-0.66$ & $0.26,0.56$ & $0.01,0.74$ \\
\hline \multicolumn{4}{|l|}{ Clamp } \\
\hline $\operatorname{EGP}\left(\mathrm{mg} / \mathrm{m}^{2} / \mathrm{min}\right)$ & $0.31,-0.71$ & $0.54,0.08$ & $0.60,-0.21$ \\
\hline $\mathrm{DI}(\mathrm{IS} \times \Delta \mathrm{I} 30)$ & $-0.72,^{c} 0.44$ & $0.50,-0.65$ & $-0.27,0.22$ \\
\hline $\operatorname{MCR}(\mathrm{mL} / \mathrm{min})$ & $-0.46,0.18$ & $0.30,-0.26$ & $-0.38,0.05$ \\
\hline IMGD (mg/m²/min) & $0.34,-0.21$ & $-0.09,0.51$ & $0.35,0.32$ \\
\hline
\end{tabular}

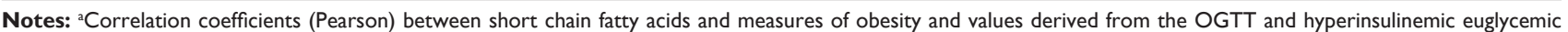

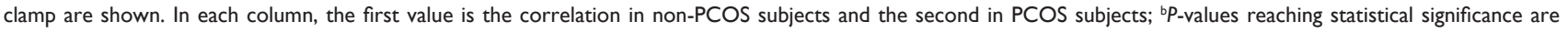
indicated in the parentheses; 'of note, a significant association between acetate and DI was not found despite high correlation value because only seven non-PCOS subjects had DI values calculated.

Abbreviations: PCOS, polycystic ovary syndrome; BMI, body mass index; VAT, visceral adipose tissue; FAT, percentage fat mass $\times$ body weight; OGTT, oral glucose tolerance test; EGP, endogenous glucose production; DI, disposition index; MCR, metabolic clearance rate of insulin; IMGD, insulin mediated glucose disposal.

\section{Publish your work in this journal}

Diabetes, Metabolic Syndrome and Obesity: Targets and Therapy is an international, peer-reviewed open-access journal committed to the rapid publication of the latest laboratory and clinical findings in the fields of diabetes, metabolic syndrome and obesity research. Original research, review, case reports, hypothesis formation, expert opinion and commentaries are all considered for publication. The manuscript management system is completely online and includes a very quick and fair peer-review system, which is all easy to use. Visit $\mathrm{http}: / / \mathrm{www}$.dovepress.com/testimonials.php to read real quotes from published authors. 